\title{
Developing Language Skills through Students' Quality Circle (SQC) Way: An Innovative Approach to Language Teaching and Learning
}

Lekhnath Pathak

Tribhuvan University, Nepal lekhnathspathak@gmail.com

Abstract

This article proposes SQC frameworkfor English language education. The meaningful context in which the language activities take place as the students work through the cycle of problem solving provides rich opportunity to develop their language skills. Theoretical, conceptual and historical background and framework, stages of SQC case study, tools and techniques used in problem solving to develop the students' personality, language and SQC interface and sample SQC case study have been discussed in this paper. The potential of SQC leading to TQC for professional development and its potential to inform and refine the ELT curriculum has been proposed. The systematic and scientific approach that SQC adopts has tremendous future potentials in academia.

Keywords: Students' Quality Circle (SQC), language teaching, language learning, English education, language and SQC interface

\section{Introduction}

Students' Quality Circle (SQC) can be defined as a small group of motivated voluntary students of the same educational institute, who meet regularly in the study place for a particular period, to identify, analyze and solve their mutual problems using scientific problem solving tools and techniques for their self and mutual development (Hutchins, 2008; Chapagain, 2013). It is an approach to prepare a Total Quality Person (TQP), which is a component of Total Quality Management in Education, which follows the concept of Total Quality Management (TQM). It uses problem solving skills as a means to develop a child into a complete human being (Pathak, 2009) by developing his/her personality.

The objective of SQC is to produce students, who are: GOOD and SMART. The attributes of these two values can be summed up in terms of dichotomies as given in the following table (for more details and elaboration of these attributes, see Pathak, 2010) 


\begin{tabular}{|l|l|}
\hline Good & Smart \\
\hline Heart & Head \\
Emotion & Reason \\
Feeling & Thinking \\
Spiritual self & Material self \\
Qualitative & Quantitative \\
Oriental & Occidental \\
Theoretical & Practical \\
Deductive & Inductive \\
Social & Individual \\
Others & Self \\
Serving & Consuming \\
Giving & Receiving \\
Cooperative & Competitive \\
Speculative & Calculative \\
Synthetic & Analytic \\
Creative & Critical \\
Right brain & Left brain \\
Holistic & Minimalistic \\
Verbal & Numerical \\
Circularity & Linearity \\
Strategic & Operational \\
\hline
\end{tabular}

SQC approach to train students the core values of being GOOD and SMART is to "CATCH THEM YOUNG": Scripting on the clean board is better than deskilling adults (Chapagain, 2013). As the children are still growing, their mind is like a clean board or tabula rasa so it is possible to script anything in their young and growing mind. It becomes difficult to erase the wrong learning from an adult mind where all the impressions are etched more permanently. Instead of putting a grown up through the processing of learning, unlearning and relearning, it is easier and more meaningful to form the right impressions in a growing mind.

Following are some of the personality traits developed while performing SQC activities (Chapagain, 2013): 
Self-confidence and desire to excel

Self-discipline and better manners

Interpersonal and public relations

Positive attitude and empathy

Social responsibility

Time management skills

Scientific problem solving skills

Communication and presentation skills

Creativity and lateral thinking habits

Working habits in a team

Broader vision and academic knowledge

SQC is an all-encompassing framework for academics in general and language teaching-learning in particular. Many of the past methods from Grammar Translation Method to recent Communicative Language Teaching Method have had their own successes and failures and none of them have really proved infallible, in fact, none of the method can be infallible. One pervasive similarity in all these methods were - they either were teacher focused or student focused rather than event focused and were all inspired by linguistics or applied linguistics. SQC comes from a non-linguistic domain but with greater potentials for applied linguistics and ELT. It brings practical situation requiring the use of language at multiple levels where the learners get a chance to use language in a varied ways.

\section{Theoretical, Conceptual and Historical Background/Framework}

SQC, as an innovative concept, started with Ishikawa introducing Quality Control Circles in Japan in the 60's and 70's of the 20 th century (Ishikawa, 1970) in collaboration with Japanese Union of Scientists and Engineers (JUSE) to improve the quality of production and service industry using statistical tools. Subsequently, a set of tools called QC tools were developed (Nayatami et al, 1984). JUSE has further refined and standardized the concept of Quality Control Circles (QC Circle Headquarters, 1996, 1997, 2010). Hutchins $(1983,1989)$ introduced this concept in the UK.Quality Circle can be likened to and can be said as a better version of Action Research (Greenwood \& Levin, 1997; Fricke \& Totterdill, 2004; Greenwood et al, 1991). David Hutchins recent book Quality Beyond Borders makes the concept of quality all permeable to different fields of life (Hutchins, 2019). 
A major breakthrough in Quality Circles from production and service industry to academia happened when a small group of 13-14 year old students from City Montessori School (CMS) of Lucknow, India presented their case study in an international conference of Quality experts in Hongkong in 1994, using the QC tools to solve their own problems. Immediately a need to introduce this concept was felt by the experts of the field and under the chairmanship of Jagadish Gandhi, the founder of the CMS, an organization called World Council for Total Quality and Excellence in Education was established in 1999 (Gandhi, 1999). This marked the beginning of Quality Circles in academia which spread in South Asia with India, Bangladesh, Nepal, Pakistan and Sri Lanka (one of its provinces - Sabaragamuwa Province has made Quality Circle as the driving philosophy of governance with Chief Minister and Chief Secretary themselves promoting the concept in all government agencies including academic institutions) by introducing the concepts in schools. Through the founders of WCTQEE, it spread to countries like America, UK, Mauritius and Turkey. In Mauritius, it is countrywide. In UK, Richard Ennals introduced this concept to his management students in Kingston University connecting the concept with working life, empowerment, and collaborative advantage and creating a community of circles (Ennals, 2012; Ennals \& Salomon, 2011; Ennals \& Hutchins, 2012). He even encouraged a Nepali student doing MSc in Management with him to write a dissertation on the SQC being implemented in Nepal (Gurung, 2013).

In Nepal, SQC was initiated by Dinesh Chapagain in 1999, who was also one of the founders of WCTQEE. It took a formal shape in 2006 with the establishment of QUEST-Nepal (Quality Circles in Education for Students' Personality Development), an organization dedicated to training students and teachers on doing and implementing SQC. Ever since its establishment, it has been regularly organizing annual conventions where school students from different parts of Nepal showcase their case studies on their own problems that they identified, analyzed and solved by themselves and so far this is the only academic forum in Nepal for students to meet and deliberate annually on issues pertaining to students' practical and academic life. So far QUEST-Nepal has organized 14 national annual conventions regularly since 2005 and one international convention in 2013 and remains only platform for the students to showcase their case studies and engage in academic practice annually at national and international level where on average 1500 students participants selected from different parts of Nepal attend. Currently, SQC is being implemented in 158 schools in 14 districts and 22 hubs across Nepal (Saud \& Pathak, 2019). With the movement ever growing, it has trained over 1200 teachers and 100,000 students. 
The major difference between the Quality Circle initiated by JUSE in 1962 in Japan, by CMS in India in 1992 and by QUEST-Nepal in Nepal in 2006 is generational, with first, second and third generation respectively (Chapagain, 2018). They are qualitatively different. In terms of purpose, the first is focused on improving the quality of the services and products and workers' self and mutual development, the second focuses on preparing total quality people for total quality management, the third focuses in developing students as good and smart citizens for the nation. In terms of application, first is concerned with voluntary participation of workers, the second is concerned with voluntary participation of students in QC as extracurricular activity, the third is concerned with compulsory participation of all students in QC as curricular activity. In terms of using tools, the first uses 7 basic QCC tools and new management and industrial engineering tools, the second uses only 7 basic QCC tools, the third uses 12 SQC tools. In terms of addressing problem types, the first addresses productivity and service quality problems, the second addresses students', educational institutions', societal and national problems, the third addresses problems specific to students. The element that connects all the three generation Quality Circles is the techniques used to solve the problems - all three apply the technique of identifying, analyzing and solving problems.

\section{Methodology: How Does it Work?}

It is a scientific and systematic approach. So it has to follow some standard operation procedures in order to achieve the desired results. It follows a standard course of action of seven steps as listed below:

1. Identifying Your Problem: Select Topic

i Identify participants' role

ii Identify and list participants' problems

iii Prioritize and select one topic

2. Set Target

i Identify characteristics of the problem

ii Observe minutely the characteristics

iii Set targets for analyzing and solving

3. Analyzing Yourself the Problem: Plan Activities

i Decide activities

ii Decide schedule

iii Draw action plan 
4. Analyze Causes

i Identify primary causes

ii Analyze root causes

iii Analyze relationships

iv Decide causes to tackle

v Identify countermeasures

5. Solve Your Problem Yourself: Implement Countermeasures

i Decide countermeasure activities

ii Draw implementation plan

iii Implement plan

6. Check Results

i Evaluate results

ii Compare results with target

7. Standardize Control and Continue: Standardize Control

i Standardize the System

ii Educate and Train Others

iii Monitor to Maintain the System

The above stages are realized by working with the 12SQC tools which are 7 QCC tools, 2 management tools and 3 behavioral scientific research tools (Chapagain, 2018) which are used at various stages of problem solving. Following are the twelve SQC tools:

1. Check Sheet - To collect data

2. Graphs and Charts - Plotting and organizing data

3. Histogram - Plotting and organizing data

4. Pareto Diagram - To prioritize the problems

5. Cause and Effect Diagram - to systematically summarize the relationships between problem characteristics and the result

6. Scatter Diagram - to check for correlation between the sets of data

7. Control Chart - to check whether a method adopted for an activity or a process is within control or not. 
8. Paired Ranking Diagram - for comparing and prioritizing various causes, effects or problems

9. Radar Chart - to display multivariate data in the form of a two dimensional chart of three or more quantitative and qualitative variables

10. Activity Planning Matrix - to spell out all required parameters to perform any activity for specific purpose realized in the form of $5 \mathrm{~W} 1 \mathrm{H}$ (Who, What, Where, When, Why and How)

11. Affinity Diagram - to synthesize large amounts of language data (ideas, opinions, issues) and to organize them into sub-groupings and groupings based on their natural relationships

12. Tree Diagram - to break down broad categories of activities into finer and finer levels of detail.

\section{Language and SQC Interface}

For a successful language development, language activity should take place in a meaningful and productive environment. SQC activity provides the right kind of environment to a learner to practice various aspects of language in a rich and meaningful setting. The followings are the key aspects developed through the interface of language and SQC:

Both theoretical and applied areas of linguistics get touched in SQC activities. Though the students practicing SQC may not be aware of theories of language and its applied aspects, they do have a clear idea of what language should achieve for them. In order to bring the project to a successful fruition, they have to make use of effective communication by putting the language in the best possible manner.

Phonetics for proper pronunciation and articulation. The ultimate goal of the SQC project work is to present it for a larger audience to showcase their study and disseminate the results of their positive intervention. Presentation of the case study is a way of disseminating their knowledge and thus motivating and training others to follow suit. In order to present well to the larger audience, the students have to work on the appropriate pronunciation and correct articulation of their ideas. Thus, without even realizing it, the students are already working on the phonetics/phonology of the language. 
Morphology for forming any new words as required. Morphology is all about word formation. As the students keep working on their project, they come across and encounter new ideas and issues for which the existing vocabulary may not be sufficient to capture the sense they want to convey. So they can coin new words to match their idea or play with the existing vocabulary to use the language creatively. In every stage of their task, they have to document their actions which makes them work on the language, formulating appropriate words.

Syntax for putting ideas together effectively. The right words have to be put in the right syntax to make the expression meaningful. The students have to minute the activities regularly to document the process and steps taken to solve their problem. The documentation and dissemination process effectively enhances their syntactic knowledge and abilities.

Semantics for getting the idea across to the audience. What the students have achieved have to be encapsulated in meaningful way and needs to be communicated in such way that their accomplishment is conveyed unambiguously. They learn to resolve ambiguities as they work on their project and prepare to present it to the audience.

Discourse for coherence and cohesion of ideas. All the ideas have to be put together and organized in such a way that there is a harmonious coherence and cohesiveness of the ideas and actions. The students learn it by doing as they progress through the task. The entire problem solving case study has to emerge like a complete story at the end. So appropriate discourse devices are used in telling the story of their success to the audience.

\section{Language Skills and SQC}

The following language skills are expected to be developed through SQC:

Listening. Students learn to listen to each other's ideas, problems, solutions, analyses. To move the project ahead, it is important that they share their ideas and listen to each other. Skill to grasp other's ideas and assimilate them with their own is an important aspect of SQC.

Speaking. Every student of the circle has to contribute ideas meaningfully and finally make presentation of the case study. Ideas keep flowing as the members of the group float their ideas, express dissent when they don't agree with other's ideas and to resolve the conflict with each other if there are conflicting ideas and finally to give a single voice by incorporating the voices of every member of the 
circle, all leads to the development of speaking skills. In fact, SQC provides such a rich opportunity for speaking that a Fluency Hypothesis has been proposed around the concept of SQC (Mir, 2012). How SQC helps in attaining fluency is discussed below separately.

Reading. Students have to find out relevant information, write up and literature and garner ideas from them in order to get required knowledge, data and information to support and enlighten their case study. To understand the current scenario of their problem in broader socio-economic and political perspective, they need to educate themselves by sufficient reading on the case under study. This introduces them to the idea of importance of literature review in any research work.

Writing. At every stage of problem solving all the activities have to be minutely documented. They need to find the right expression as they document their progress. Recording the ideas coming from brainstorming, writing a report of their entire case study trains them to write in systematic and coherent manner. Just by adopting SQC approach in teaching writing to the students, even without doing the entire SQC project, they have been found to show improvement in their writing skills (Parajuli, 2012).

\section{SQC in Attaining Fluency}

SQC is equally significant to develop fluency of the students. The following activities are embedded to SQC in attaining fluency:

Opportunities to produce speech. In SQCs students do brainstorming. At the initial stages, they just supply words, phrases or clauses.After the brainstorming, students incubate the ideas. In the sessions after incubation, students accept or reject the ideas presented and words are unwrapped. They explain those words and phrases and give arguments to substantiate their ideas. These are the opportunities when they produce speeches.

Conceptualizing and formulating ideas. All concepts are discussed in detail during brainstorming so they learn to clarify their concepts and ideas. Simultaneously they formulate new ideas, as they are encouraged to be creative through lateral and creative thinking.

Fixing incorrect expressions. In weekly meetings students express their ideas freely and thus improve on their faulty structures by self-correction or by facilitator/peer feedback. Students have to present the case study to different 
audiences, so they practice a lot and thus fix the problems of structure or grammar. They repeat same steps many times at different levels. By doing so they achieve automaticity of correct expression.

Articulation. Clarity of mind helps clear articulation. All speech organs work harmoniously when ideas are in sequence at the threshold of mentalisation. Conceptualization and articulation go in parallel. Every individual member of the circle has to formulate, speak up and share ideas.

Self-analysis. When a student explains the procedure adopted during different stages of sessions, he/she speaks according to an act that has taken place in the recent past in reality. Thus all the processes are recalled in the mind of the student and he/she analyses his/her actions as well as his/her expression that is being used to explain the activity.This allows a student to do an introspection of his/her actions and expressions.

Conditioned response. A degree of conceptualization, formulation, articulation and self-analyses is required to achieve the fluency. Repeated different responses bring about a kind of automaticity. During the process of presentations at different levels - from brainstorming to final presentation of the report to a larger audience, students use prefabricated chunks of sentences and phrases, and this is the most important requirement to attain fluency. The repeated use of such expressions develops the confidence to speak fluently.

Socio-cultural and political aspect. Students always take into account the socio-cultural aspect of a problem. In a target language only such expressions are used in case study presentations, which are socially and culturally acceptable. Students also have to be aware of the political ramification of the problem in hand, so this allows them to put language in a larger perspective which helps to make them fluent as they speak knowledgably.

Language functions. During meetings, students speak to convey a message, report activities, socialize, debate, negotiate, agree or disagree, plan, evaluate, implement, resolve conflict, reach consensus, come to a conclusion, make a presentation. Thus, students practice different language functions during the course of problem solving cycle.

Pragmatics of the language. Pragmatics is the relationship between the language and the context and appropriate use of the language in the given context. When students choose appropriate problem-solving tools and techniques and 
use them to solve the problem they have decided upon, they have to justify each and every decision. So the language is used in a meaningful context when they are practicing SQC.

Grammar. In order to analyze a problem and describe the methods used to handle it, students need to use correct grammar, otherwise the idea is neither conveyed nor accepted by other members of the circle. This develops the habit of learning appropriate grammar to describe a process or situation and put the expressions in right perspective.

Vocabulary. Students use appropriate vocabulary to express their views and narrate the procedure and their findings at every level.Different types of vocabulary that they develop through this process are: (a) Definition words: while defining various concepts they need to use the words that can define their idea exactly; (b) Concrete and abstract words: in mentioning the tangible and intangible benefits gained from the case study. After they have completed the project and present it to the audience, they also need to tell about the lessons learnt and the benefits they achieved while solving the problem. Usually, the benefits are expressed as tangible and intangible benefits - tangible benefits are external benefits - those that are directly apparent through the senses and can be seen as a result of the intervention made by the students, whereas intangible benefits are more internal benefits like developing mutual respect for each other, learning to work as a team, being empathetic to others issues and so on.

\section{An Example of a Case Study}

Following is an example of a case study that one circle of students has undertaken. This case was undertaken by LAHS Hostelites Circle and was presented in the $8^{\text {th }}$ National Convention of Students' Quality Circle organized by St. Xavier's School, Jawalakhel, Lalitpur in 2008. It illustrates the components that we have discussed above. Interestingly, the students have taken up a case related to English language which may enlighten teachers of English how SQC functions to develop multiple dimensions of language. The details of the case study is given here:

Situation. A group of 8, Grade 9 hostel students, average age 14 studying in a reputed private English medium boarding school.

Problem identification. Upon first series of brainstorming on their problems, they list the following 25 problems: 
Lack of English speaking environment

Formation of gangs

Shyness/ lack of confidence

Smoking / Bunking classes

No encouragement for academically weak boarder students

Insufficient resources for holiday activities

Unhygienic cafeteria

Teachers unaware of students' problems

Too many theory classes, less practical classes

Long morning assemblies

Too much homework /no time for studies

Use of filthy language

Monotonous hostel routine

Ragging and bullying

Offensive graffiti on the wall

Teaching without proper explanation/ teaching at high speed

Less time for ECA

Discrimination between boarders and day scholars

Discrimination among friends

Dirty and under-maintained toilets

Unfriendly teachers

No counselling sessions

Crowded dining hall

No outing

By applying prioritization techniques the students narrow down the listen problems to following 7 problems of which "Lack of English Speaking Environment" get top priority. Besides, some other problems are as follows:

Lack of English speaking environment

Shyness / lack of confidence 
Teaching without proper explanation

Smoking and bunking classes

Ragging and bullying

Less time for ECA activities

Use of filthy language

The students define the problem of "Lack of English Speaking Environment" as "the environment that discourages students to speak English. It is unavailability of appropriate condition which motivates students to communicate in English. It is a major problem in our school. It has hindered our ability to converse effectively and become less misunderstood".

Next, the students list out the negative effects that the lack of English speaking environment has on them. The effects are low self-esteem which leads to non-involvement in group discussions, feeling of being misunderstood, feeling insignificant that leads to quarrel at times, feeling avoided and unwelcome, feeling irritated and unaccepted, giving meaningless answers that lead to poor marks in tests or exams which shows poor academic performance and ultimately leads to depression. And the total effect of all these effects they feel on themselves is poor personality, leading to a huge failure in life.

Once the students have listed out the multiple effects of their identified problem, they get down to do a cause-and-effect analysis with the help of cause-and-effect diagram or Ishikawa diagram. They have grouped the causes of the problem under six ' $M$ ' headings:

Materials: Newspapers for reading; tapes, CDs, DVDs for listening; insufficient library resources; dictionaries for consulting meanings of words; English literature for wider reading

Method: No guidance and encouragement from teachers and school; no motivating programs; no monitoring for use of English; no strict rules language use

Machines: lack of or non-availability of internet, multimedia computer, audiovisual devices, projector

Man (human beings): Friends, teachers, staff/workers, parents/guardians, school management not supportive enough to provide the right environment for the use of English 
Mother Nature (Environment): playground, cafeteria, roadways, dining hall, dormitories are the places where English may be used but there is no encouragement for the use of English in these areas.

Management (of habits): The students list out their own habits which they have not been able to manage and that comes in the way of their speaking English like they being - disinterested, ignorant/unaware, shy/hesitant/unconfident, negligent/lazy, uncommitted, fear of making mistakes and being ridiculed, fearful of speaking/stage fright

After categorizing the causes that led to the lack of English speaking environment, the students prioritize ten most important root causes that need to work on which are: fear of being ridiculed, lack of self-confidence, fear of making mistakes, shyness, lack of motivation and encouragement, parents and teachers not communicating in English, no strict rule and regulation, unsupportive peer group/friends.

Once they prioritized their root causes leading to lack of English speaking environment, the students came up with counter measures to eliminate the causes and create and English speaking environment. They Organized meetings with their hostel in-charges and with the teachers teaching in their classes and below. They also invited experts in English language and organized motivational lectures on improving English. They prepared placards and slogans on raising awareness and to create environment for the use of English. They also monitored on the effectiveness of their measures. They persisted with implementation plan even if they were laughed at on some occasions.

With their intervention, the students were able to create an environment where their fellow students started speaking English more significantly than they had done before.

Not only did the students achieve some success in changing the academic environment of the school in their desired manner, they also benefitted in many respects while being involved in this case study. They reported that instead of opposing the change or being indifferent to the change, they learned to be the proactive agent of change. They also developed critical and creative thinking skills as they worked through the project. They developed team spirit and team working habit. They developed more self-confidence and learned to be more self-disciplined. They learned to cultivate better interpersonal and public relations and also developed better communication skills. They also learned to be more socially responsible and learned time-management skills by completing 
the project within a certain time-frame. They developed scientific and analytical skills and learned to create a broader vision of going beyond school textbooks and taking leadership in their own pressing problems.

\section{SQC as Experiential Teaching/Learning}

In this approach, learning comes from the field experience - it enables students to acquire any target language out of classroom boundaries, thus acquire fluency in natural setting. SQC is not language specific - it is language neutral. So it is possible to apply this approach in any language, be it L1 or L2.Students are given carefully structured tasks. They go out in different classes of the school or community for surveys and ask prefabricated questions. These questions are rehearsed many times.Students observe, analyze and synthesize at different stages of problem solving.

\section{Conclusion}

SQC can be used to teach not just language skills but also to develop life skills and values (Pathak, 2011a). Students' Quality Circles (SQC) should inspire Teachers' Quality Circles (TQC)for their professional development (Pathak, 2011b). It is a great tool to develop quality leadership (Ali, 2013). Concepts, tools and techniques from TQM are equally relevant in ELT. SQC holds a great potential for academic enterprise and exercise (Pathak, 2009b). If language teaching curriculum can be designed and implemented using SQC framework, it may solve the problems many teacher educators of English face in enhancing the quality of English education.

SQC is a way of empowering students by engaging them in activities of selfgrowth and leadership development that leads to their personality development. Language development is a by-product of overall growth of the students by being involved in solving their own problems. Thus for language teaching departments in the schools and universities, this could become a game-changer in language teaching-learning pedagogy. 


\section{References}

Ali, S. (2013). Building bridges between quality and leadership. Maple Creek Media: Hampstead.

Chapagain, D. P. (2019). Guide to students' quality circle: An approach to prepare total quality people ( $3^{\text {rd }}$ ed). Lalitpur: QUEST-Nepal.

Chapagain, D. P. (2018). Students' quality circle: Third generation of quality control circles (qcc) redesigned and applied for students' pro-social personality development at schools. In Handbook of $14^{\text {th }}$ National Convention on Students' Quality Circle, QUEST-Nepal and Galaxy Public School: Kathmandu.

Ennals, R. (2012). Quality as empowerment: Preparing for take off. Quality World, 32-35.

Ennals, R. \& Salomon, R. (Eds.) (2012). Older workers in a sustainable society. Frankfurt: Peter Lang.

Ennals, R. \& Hutchins, D. (Eds.) (2012). Community of circles. Special Issue, Al \& Society, 27(3).

Fricke, W. \& Totterdill, P. (Eds.) (2004). Action research in workplace innovation and regional development. Amsterdam: Benjamin.

Gandhi, J. (1999). Chairman's address note on the occasion of foundation of world council for total quality and excellence in education (WCTQEE), CMS, Lucknow, India, $23^{\text {rd }}$ February.

Greenwood, D., Santosh, J.L.G., Alonso, J.C., Markaide, I. G., Arruza, A. G., Nuin, I.L. \& Amesti, K. S. (1991). Industrial democracy as process: Participatory action research in fagor cooperative group of Mondragon. Van Gorcum: Maastricht.

Greenwood, D. \& Levin, M. (1997). Introduction to action research. Sage: Thousand Oaks.

Hutchins, D. (1983). Quality circles handbook. London: Pitman.

Hutchins, D. (1989). In pursuit of quality. London: Pitman.

Hutchins, D. (2008) Hoshin Kanri: The strategic approach to continuous improvement. London: Gower.

Hutchins, D. (2019). Quality beyond borders: Dantotsu or how to achieve best in business. London: Routledge.

Ishikawa, K. (1970). Quality control circles. Tokyo: Japanese Union of Scientists and Engineers.

Gurung, K. (2013). Quality as empowerment: An analysis of students' quality circles in Nepal to develop an innovative perspective in corporate social responsibility (CSR). MSc in Management Consultancy Dissertation, Faculty of Business and Law, 
Kingston University: London.

Mir, A. W. (2012). SQC and the fluency hypothesis. Al \& Society, 27(3).

Nayatami, Y., Eiga, T., Futamiand, R. \& Miyagawa, H. (1984). The seven new qc tools. Tokyo, Japan: 3 A Corporation.

Parajuli, B. (2012). Developing writing skills through SQC activity. M.Ed. Thesis submitted to the Department of English Education, Faculty of Education, Tribhuvan University, Nepal

Pathak, L. S. (2009 a). Evolution of a child into a complete human bein in Handbook for $5^{\text {th }}$ National Convention on Students. Quality Circle, QUEST-Nepal and Galaxy Public School: Kathmandu.

Pathak, L. S. (2009 b). Guniya chakrako sambhavana (Possibility of Quality Circle): An article about Students' Quality Circle in Kantipur National Daily on 27 November 2009.

Pathak, L. S. (2010). Smart and good: What does it mean and what it means to think beyond these borders. Handbook of $13^{\text {th }}$ International Convention on Students' Quality Circle, November 1-3, 2010, QUEST-Nepal : Kathmandu.

Pathak, L. S. (2011). SQC for developing values and skill among students in convention. Handbook of $7^{\text {th }}$ National Convention of SQC, Shuvatara School and QUEST-Nepal : Kathmandu.

Pathak, L. S. (2011). Quality circle for professional development A paper presented (with $S$. Dahal) in the $1^{\text {st }}$ International English Language Teacher Educator Conference, Hyderabad, India.

QC Circle Headquarter .(1996). Fundamentals of QC circles. Tokyo, Japan: JUSE.

QC Circle Headquarter (1997). How to operate QC circle activities ( ${ }^{\text {nd }}$ Ed.). JUSE: Tokyo, Japan.

QC Circle Headquarters (2010). A book on fundamentals of QC circles-QC circle Koryo. $\left(2^{\text {nd }} E d.\right)$, JUSE: Tokyo, Japan.

Saud, T. \& Sharma, P. L. (2019). Quality circle for quality education: A student centered approach. Paper presented in $3^{\text {rd }}$ International Conference on Quality Education, $24-26$ August 2019, Organized by Rato Bangla Foundation, Lalitpur, Nepal. 